\title{
Angiographic and clinical outcomes after percutaneous coronary intervention using a drug coated balloon in small coronary artery disease
}

\author{
(iDZvonimir Ostojić* \\ (DKlara Klarić, \\ DMarijan Pašalić, \\ DKristina Marić Bešić, \\ (D) Maja Strozzi, \\ (DIvan Škorak, \\ (D)Hrvoje Jurin, \\ DBoško Skorić, \\ (DEduard Margetić, \\ DJoško Bulum
}

University of Zagreb School of Medicine, University Hospital Centre Zagreb, Zagreb, Croatia
KEYWORDS: coronary artery disease, percutaneous coronary intervention, drug coated balloon CITATION: Cardiol Croat. 2021;16(1-2):43 | https://doi.org/10.15836/ccar2021.43

*ADDRESS FOR CORRESPONDENCE: Zvonimir Ostojić, Klinički bolnički centar Zagreb, Kišpatićeva 12, HR-10000 Zagreb, Croatia. / Phone: +385-91-8950702 / E-mail: ostojiczvonimir@gmail.com

ORCID: Zvonimir Ostojić, https://orcid.org/0000-0003-1762-9270 • Klara Klarić, https://orcid.org/0000-0002-4180-692X Marijan Pašalić, https://orcid.org/0000-0002-3197-2190 • Kristina Marić Bešić, https://orcid.org/0000-0002-4004-7271 Maja Strozzi, https://orcid.org/0000-0003-4596-8261 • Ivan Škorak, https://orcid.org/0000-0002-4900-4876 Hrvoje Jurin, https://orcid.org/0000-0002-2599-553X • Bosko Skorić, https://orcid.org/0000-0001-5979-2346 Eduard Margetić, https://orcid.org/0000-0001-9224-363X • Joško Bulum, https://orcid.org/0000-0002-1482-6503

IIIIIIIIIIIIIIIIIIIIIIIIIIIIIIIIIIIIIIIIIIIIIIIIIIIIIIIIIIIIIIIIIIIIIIIIIIIIIIIIIIIIIIIIIIIIIIIIIIIIIIIIIIIIIIIIIIIIIIIIIII

Introduction: Smaller stent diameter represents risk factor for target lesion failure (TLF). Drug coated balloons (DCB) could represent valid substitution for stents in selected patients. ${ }^{1}$ The aim of the study was to assess clinical and angiographic outcomes after percutaneous coronary interventions (PCI) using DBC in treatment of coronary arteries $\leq 2.5 \mathrm{~mm}$

Patients and Methods: Study included 222 patients treated with DCB between January 2012 and June 2019. All baseline procedures and consecutive coronary angiographies were reviewed to determine indication, lesion complexity, vessel size and procedural success. Baseline and follow up clinical data were extracted from hospital digital database.

Results: Mean patient age was 63.8 \pm 10.6 years, with the majority being men ( $N=162,73 \%$ ). In total 108 (48.6\%) patients were hospitalized due to acute coronary syndrome (ACS), of which 28 (12.6\%) had ST segment elevation myocardial infarction. Altogether, 107 (48.2\%) patients had multivessel disease and $84(37.8 \%)$ had bifurcation stenosis. DCB was most often used $(59 \%, \mathrm{~N}=131)$ in the treatment of side branches. Mean DCB diameter and length were $2.18 \pm 0.23 \mathrm{~mm}$ and $20.4 \pm 5.4 \mathrm{~mm}$, respectively. Overall, procedural success was $92.8 \%$, with $16(7.2 \%)$ cases requiring "bail out" stent implantation. Regarding angiographic follow up, 111 (50\%) patients underwent repeated coronary angiography (21 (19\%) due to ASC). Mean time to repeated coronary angiography was $12.4 \pm 15.9$ months. TLF was observed in 14 (12.6\%) patients, of which 9 (8.2\%) underwent target lesion PCI. After multivariable analysis, longer baseline procedure and fluoroscopy duration, higher volume of contrast administered and total Kerma air exposure were in positive correlation with TLF. Mean time of clinical follow up was $30.3 \pm 25.8$ months, with 43 (19.4\%) patients lost in follow up. Regarding clinical outcomes, angina improvement was observed in 149 (28.2\%) of cases. Out of 53 (29.6\%) patients examined in emergency department, 36 (20.1) were urgently hospitalized and 4 (2.2\%) died.

Conclusion: Utilization of DCB in treatment of coronary arteries $\leq 2.5 \mathrm{~mm}$, when stent implantation is not feasible, provides good angiographic and clinical long-term outcome. More complex interventions represent risk factor for TLF. Further studies are needed to confirm presented results.

LITERATURE IIIIIIIIIIIIIIIIIIIIIIIIIIIIIIIIIIIIIIIIIIIIIIIIIIIIIIIIIIIIIIIIIIIIIIIIIIIIIIIIIIIIIIIIIIIIIII

1. Jeger RV, Eccleshall S, Wan Ahmad WA, Ge J, Poerner TC, Shin ES, Alfonso F, Latib A, Ong PJ, Rissanen TT, Saucedo J, Scheller B, Kleber FX; International DCB Consensus Group. Drug-Coated Balloons for Coronary Artery Disease: Third Report of the International DCB Consensus Group. JACC Cardiovasc Interv. 2020 Jun 22;13(12):1391-1402. https://doi.org/10.1016/j.jcin.2020.02.043
RECEIVED:

December 13, 2020

ACCEPTED:

December 18, 2020

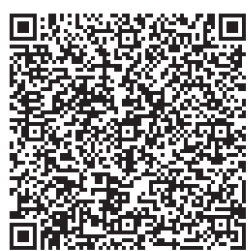

